\title{
Resistência Natural da Madeira de Sclerolobium paniculatum Vogel a Cupins em Condições de Laboratório
}

\author{
Patricia Hellenn Stallbaun ${ }^{1}$, Edy Eime Pereira Barauna ${ }^{2}$, Juarez Benigno Paes ${ }^{3}$, \\ Nadrielle Charles Ribeiro ${ }^{1}$, Thiago Campos Monteiro ${ }^{2}$, \\ Marina Donária Chaves Arantes ${ }^{3}$
}

\begin{abstract}
${ }^{1}$ Departamento de Engenharia Florestal, Universidade Federal do Tocantins - UFT, Gurupi/TO, Brasil ${ }^{2}$ Instituto de Ciências Agrárias, Universidade Federal de Minas Gerais - UFMG, Montes Claros/MG, Brasil ${ }^{3}$ Departamento de Ciências Florestais e da Madeira, Universidade Federal do Espírito Santo - UFES, Jerônimo Monteiro/ES, Brasil
\end{abstract}

\begin{abstract}
RESUMO
O objetivo do trabalho foi avaliar a resistência natural da madeira de carvoeiro (Sclerolobium paniculatum Vogel) a cupins xilófagos em ensaio de alimentação forçada. Para a avaliação da resistência da madeira foram utilizadas 9 toras, de cuja região periférica do cerne foram retiradas 45 amostras de $2,54 \times 2,00 \times 0,64 \mathrm{~cm}$ (longitudinal $\times$ radial $\times$ tangencial), sendo 5 de cada planta. Foram utilizadas amostras de madeira de Pinus sp. como padrão de comparação. O experimento foi conduzido em frascos de vidro de $600 \mathrm{~mL}$ contendo $200 \mathrm{~g}$ de areia e $1 \pm 0,05 \mathrm{~g}$ de cupins do gênero Nasutitermes. Transcorrido o período de ensaio, observou-se que o dano causado pelos térmitas à madeira foi somente superficial. Pela análise geral dos dados, a madeira da espécie testada foi classificada como altamente resistente ao ataque dos cupins, podendo ser indicada para uso em locais com incidência desses insetos.
\end{abstract}

Palavras-chave: biodeterioração da madeira, ensaio biológico, alimentação forçada.

\section{Natural Resistance of Sclerolobium paniculatum Vogel Wood to Termites in Laboratory Conditions}

\begin{abstract}
This work aimed to evaluate the natural resistance of the coal wood (Sclerolobium paniculatum Vogel) to xylophagous termites in force-feeding assay. Nine logs were used to evaluate the wood strength, which were removed from the core peripheral region of 45 samples measuring $2.54 \times 2.00 \times 0.64 \mathrm{~cm}$ (longitudinal $\times$ radial $\times$ tangential), five from each plant. Pinus sp. wood samples were usedas a comparison standard. The experiment was conducted in $600 \mathrm{ml}$ glass bottles containing $200 \mathrm{~g}$ of sand and $1 \pm 0.05 \mathrm{~g}$ of Nasutitermes termites. Passed the test period, it was observed that the termites caused only superficial damage to the wood. The overall data analysis indicates that the tested wood was classified as highly resistant to termite attack and may be suitable for use in locations affected by them.
\end{abstract}

Keywords: wood biodeterioration, biological assay, forced feeding test. 


\section{INTRODUÇÃO}

A madeira é um material de origem biológica, versátil e renovável que pode ser utilizada na construção civil, rural ou urbana, indústria moveleira, fabricação de dormentes, postes, escoras, moirões e painéis de madeira reconstituída e como fonte de energia na forma de lenha ou carvão vegetal (Gomes et al., 2005). Apesar das características tecnológicas desse material e de seus derivados, um dos fatores que limitam sua utilização é sua baixa durabilidade natural. Assim, dependendo do local e modo de emprego, ela pode ser atacada por organismos xilófagos como bactérias, fungos, insetos e organismos marinhos (Stangerlin et al., 2013).

Dentre os insetos xilófagos, os térmitas ou cupins se destacam pelos consideráveis danos econômicos causados. Eles pertencem à ordem Isoptera, que contém aproximadamente 2.750 espécies descritas. São indivíduos sociais que vivem em colônias cujas atividades são distribuídas entre as diferentes castas (Constantino, 1999). Os maiores danos à madeira estrutural e em móveis são causados por espécies dos gêneros Coptotermes, Cryptotermes e Nasutitermes e, na arborização urbana, por Coptotermes (Bandeira et al., 1998).

O gênero Nasutitermes possui ampla distribuição geográfica, sendo um dos mais ricos em espécies. O número de indivíduos em uma colônia pode alcançar 3 milhões e sua longevidade, variar de 40 a 80 anos (Kambhampati \& Eggleton, 2000). Podem atacar madeira de várias classes de densidade e umidade (Abreu et al., 2002; Reis \& Cancello, 2007). A capacidade que o lenho possui de resistir à ação de agentes deterioradores é definida como resistência natural (Willeitner, 1984), podendo existir diferenças entre árvores de uma mesma espécie e dentro de um mesmo indivíduo (Panshin \& De Zeeuw, 1980).

Para o uso racional da madeira, a durabilidade natural é uma característica importante, pois em espécies florestais que possuem alta resistência à deterioração biológica é desnecessário o emprego substâncias químicas com o fim de ampliar seu tempo em serviço, minimizando-se o impacto ambiental e os gastos desnecessários com a reposição de peças deterioradas prematuramente e garantindo, assim, por mais tempo, a integridade da construção e a segurança das pessoas que dela fazem uso.
O Sclerolobium paniculatum Vogel é uma espécie florestal pertencente à família Leguminosae Caesalpinioideae, conhecida por carvoeiro, táxi-branco ou cachamorra, que tem se destacado pelo rápido crescimento, podendo sua madeira ser utilizada na confecção de moirões, esteios e caibros, além de como fonte para a produção de lenha e carvão vegetal e para outros usos, nas construções rurais e urbanas (Dias et al., 1992; Lorenzi, 2002; Franke, 1999; Carvalho, 2010).

O carvoeiro ocorre nas regiões Norte, Nordeste e Sudeste do Brasil em cerrados e cerradões, adaptando-se a solos pobres em nutrientes e arenosos. Possui porte médio, com 8 a $20 \mathrm{~m}$ de altura e 30 a $70 \mathrm{~cm}$ de diâmetro à altura do peito (DAP), tomado a $1,30 \mathrm{~m}$ do solo, mas pode atingir até $30 \mathrm{~m}$ de altura e $100 \mathrm{~cm}$ de DAP (Carpanezzi et al., 1983; Lorenzi, 2002; Lima, 2004). É uma espécie florestal de tronco retilíneo, com dominância apical bem definida, além de reunir características tecnológicas, ecológicas e silviculturais que a tornam promissora para plantios comerciais (Carpanezzi et al., 1983).

O conhecimento sobre a durabilidade natural do carvoeiro é importante para fornecer informações básicas a respeito de sua utilização em diferentes condições de exposição a agentes biodeterioradores. Assim, o presente trabalho teve como objetivo avaliar a resistência natural da madeira de Sclerolobium paniculatum Vogel a cupins xilófagos em condições de laboratório.

\section{MATERIAL E MÉTODOS}

\subsection{Coleta das árvores e confecção das amostras}

Para o estudo foram coletadas nove árvores de carvoeiro (Sclerolobium paniculatum Vogel), provenientes dos municípios de Dueré, latitude $11^{\circ} 20^{\prime} 46^{\prime \prime}$ Sul, longitude $49^{\circ} 16^{\prime} 14^{\prime \prime}$ Oeste, altitude de 235 metros, e de Cariri do Tocantins, latitude $11^{\circ} 53^{\prime} 25^{\prime \prime}$ 'Sul, longitude $49^{\circ} 9^{\prime} 49^{\prime \prime \prime}$ Oeste, altitude de 295 metros.

As árvores foram selecionadas em função do diâmetro a altura do peito (DAP), tomado a $1,30 \mathrm{~m}$ do solo, variando entre 20 a $25 \mathrm{~cm}$, e do aspecto fitossanitário. Após o corte, os fustes foram seccionados em toras de 2,00 m de comprimento.

Das toras foram retiradas da região periférica do cerne 45 amostras de 2,54 ×2,00 ×0,64 $\mathrm{cm}$ (longitudinal 
$\times$ radial $\times$ tangencial), sendo 5 de cada árvore. Além do carvoeiro foram utilizadas 5 amostras de madeira de Pinus sp., como padrão de comparação, conforme preconizado pela American Society for Testing and Materials (ASTM, 2005c).

As amostras foram secas a temperatura de $103^{\circ} \mathrm{C} \pm 2{ }^{\circ} \mathrm{C}$ até atingirem massa constante e pesadas em uma balança de $0,01 \mathrm{~g}$ de precisão. Determinaram-se a massa e o volume de cada amostra (ASTM, 2005a), e os valores foram utilizados no cálculo da densidade da madeira e da perda de massa dos corpos de prova causada pelos térmitas.

\subsection{Coleta da colônia e captura dos cupins}

A colônia de cupins foi coletada no campus de Gurupi, pertencente à Universidade Federal do Tocantins, Gurupi, TO. Depois da coleta, a colônia foi disposta em uma caixa d'água de $250 \mathrm{~L}$, a qual foi apoiada sobre quatro blocos cerâmicos colocado em bandejas de plástico contendo água para evitar a fuga dos cupins (Paes et al., 2013).

Para a captura dos cupins foram seguidas as recomendações de Paes (1997). Assim, foram utilizados fragmentos de papelão cortados em formato quadrangular de $20 \times 20 \mathrm{~cm}$, que foram acomodados no fundo da caixa e umedecidos com água destilada para atrair os cupins. Decorridos aproximadamente três dias os insetos migraram da colônia para o papelão.

Os fragmentos de papelão foram desmontados sobre uma bandeja e os cupins transportados para um balde de 10 litros contendo 20 toalhas de papel, sendo 10 umedecidas com água destilada, ligeiramente amassadas, que foram dispostas no fundo do recipiente, recobertas com 10 toalhas secas (ASTM, 2005c). Após 6 horas, os insetos se acomodaram por entre as toalhas, ficando os mais fracos e danificados por cima e os mais vigorosos nas úmidas. As secas foram removidas e as demais levadas para o laboratório para a coleta dos cupins.

\subsection{Preparo dos frascos de montagem do experimento}

$\mathrm{O}$ experimento foi montado em frascos de vidro de $600 \mathrm{~mL}$, lavados e esterilizados (álcool e hipoclorito de sódio), aos quais foram adicionados $200 \mathrm{~g}$ de areia esterilizada e água destilada, até o ponto de saturação, sendo mantidos em repouso por 12 horas (ASTM, 2005c).

A cada frasco foi adicionado um corpo de prova, com metade de seu comprimento inserida na areia, na lateral do recipiente e com uma face visível, e $1 \mathrm{~g} \pm 0,05 \mathrm{~g}$ de Nasutitermes. Vale ressaltar que foi tomado cuidado para que $90 \%$ dos insetos fossem operárias. Para evitar fugas e garantir a aeração nos fracos, a tampa deles foi levemente rosqueada.

Os frascos ficaram durante quatro semanas em sala climatizada à temperatura de $27^{\circ} \mathrm{C} \pm 2{ }^{\circ} \mathrm{C}$ e $75 \% \pm 5 \%$ de umidade relativa, conforme recomendação da ASTM D-3345 (ASTM, 2005c).

Foram separados cinco frascos, aleatoriamente, os quais foram pesados semanalmente, para o controle da umidade, conforme norma utilizada. Os demais foram examinados no final da primeira e da quarta semanas, a fim de detectar a presença de túneis e a posição geral dos cupins neles.

\subsection{Análise dos resultados}

Para avaliar a resistência da madeira de Sclerolobium paniculatum foram computados a perda de massa (ASTM, 2005b), o desgaste e a mortalidade dos cupins, avaliada ao término do experimento (Tabela 1).

Conforme recomendado por Steel \& Torrie (1980), os valores foram transformados em arcsen [raiz quadrada (perda de massa ou mortalidade/100)] e em raiz quadrada (nota de desgaste $+0,5$ ), a fim de permitir a normalidade dos dados (teste de Lilliefors)

Tabela 1. Avaliação do desgaste da madeira e da mortalidade dos térmitas.

Table 1. Evaluation of wood waste and termites mortality.

\begin{tabular}{lc}
\multicolumn{1}{c}{ Avaliação do desgaste } & Nota \\
\hline Sadio, permitindo escarificações superficiais & 10 \\
\hline Ataque superficial & 9 \\
Ataque moderado, havendo penetração & 7 \\
Ataque intensivo & 4 \\
\hline Falha, havendo ruptura dos corpos de prova & 0 \\
Mortalidade dos térmitas & $(\%)$ \\
Baixa & $0-33$ \\
Moderada & $34-66$ \\
\hline Alta & $67-99$ \\
\hline Total & 100 \\
\hline
\end{tabular}

Fonte: Adaptado da ASTM D-3345 (ASTM, 2005c). 
e a homogeneidade das variâncias (teste de Cochran). $\mathrm{Na}$ análise e avaliação dos ensaios empregou-se o teste de Tukey $(\mathrm{p} \leq 0,05)$ para as fontes de variação detectadas como significativas pelo teste $\mathrm{F}(\mathrm{p} \leq 0,05)$.

\section{RESULTADOS E DISCUSSÃO}

Com base nas avaliações dos corpos de prova quanto à mortalidade dos cupins, observou-se alta resistência natural da madeira de Sclerolobium paniculatum, pois promoveu alta mortalidade dos insetos, com exceção das retiradas das árvores 2 e 3 , que apresentaram taxas de mortalidade moderadas (Tabela 2).

A alta resistência biológica de algumas espécies madeireiras é explicada com base nas propriedades de seus componentes químicos, pois é consenso que existe estreita relação entre quantidade e classe de extrativos e durabilidade natural da madeira (Paes et al., 2007).

A mortalidade pode ter sido ocasionada pela ação direta dos extrativos sobre os cupins ou por desequilíbrio por eles provocado sobre os simbiontes dos insetos. A quantidade desses microrganismos presentes no intestino dos insetos pode se tornar insuficiente para digerir a celulose, influenciando o seu hábito alimentar, o que poderia causar-lhes a morte (Supriana, 1985).

Pela análise das notas de desgaste apresentadas na Tabela 2 é possível observar que as amostras retiradas das árvores 2 e 3 possuem certa susceptibilidade à ação dos cupins, apresentando ataques intensivo e moderado, respectivamente. No entanto, as amostras provenientes das demais árvores analisadas praticamente não foram atacadas, mantendo-se sadias.

Esses resultados corroboram os de Costa et al. (2005), que ao analisarem a durabilidade de madeiras tratadas e não tratadas, após 10 anos em campo de apodrecimento, concluíram que, entre as não tratadas, os moirões de Sclerolobium paniculatum foram os que apresentaram as melhores médias de sanidade quando comparados com os de Eucalyptus saligna, Eucalyptus grandis e Pinus elliottii var. elliottii, demonstrando assim ser essa uma espécie resistente ao ataque de fungos e cupins.

A madeira de Pinus sp. utilizada como padrão de comparação teve baixa perda de massa e desgaste (nota), sendo classificada como resistente a ação dos térmitas. Segundo Supriana (1985), tal fato pode decorrer de não ser hábito dos cupins se alimentarem dessa madeira - esses térmitas são muito seletivos na sua dieta, não atacando espécies com as quais tiveram pouco contato. Tal situação de fato ocorreu, pois, os indivíduos usados nesse experimento eram provenientes de colônias instaladas em áreas onde não tinham contato com essa espécie florestal.

A madeira ensaiada teve baixa porcentagem de perda de massa, no entanto os valores de resistência biológica ao térmita testado atingidos pelo lenho da árvore 2 foram inferiores, diferindo estatisticamente das demais (Tabela 2). Esse resultado pode ter sido influenciado pela idade da planta e pela qualidade do sítio, uma vez que a densidade da madeira do respectivo indivíduo também foi menor que dos demais.

Tabela 2. Valores médios da densidade básica, perda de massa, do desgaste da madeira e da mortalidade dos cupins por árvore amostrada.

Table 2. Average values for basic density, mass loss, wood waste and termites mortality by sampled tree.

\begin{tabular}{ccccc|}
\hline Árvore & $\begin{array}{c}\text { Densidade básica } \\
\left(\mathbf{g ~ c m}^{-3}\right)\end{array}$ & Perda de massa (\%) & $\begin{array}{c}\text { Desgaste } \\
(\text { Nota) }\end{array}$ & $\begin{array}{c}\text { Mortalidade dos } \\
\text { cupins (\%) }\end{array}$ \\
\hline 1 & 0,719 & $1,96 \mathrm{bc}$ & 9 & 100 \\
\hline 2 & 0,661 & $5,13 \mathrm{a}$ & 4 & 55 \\
\hline 3 & 0,706 & $3,02 \mathrm{~b}$ & 7 & 60 \\
4 & 0,731 & $1,09 \mathrm{c}$ & 10 & 90 \\
\hline 5 & 0,716 & $2,21 \mathrm{bc}$ & 10 & 100 \\
\hline 6 & 0,717 & $1,97 \mathrm{bc}$ & 10 & 100 \\
\hline 7 & 0,724 & $1,58 \mathrm{bc}$ & 10 & 100 \\
\hline 8 & 0,731 & $1,22 \mathrm{bc}$ & 10 & 100 \\
\hline
\end{tabular}

Médias seguidas pela mesma letra não diferem estatisticamente pelo teste de Tukey $(p>0,05)$. 


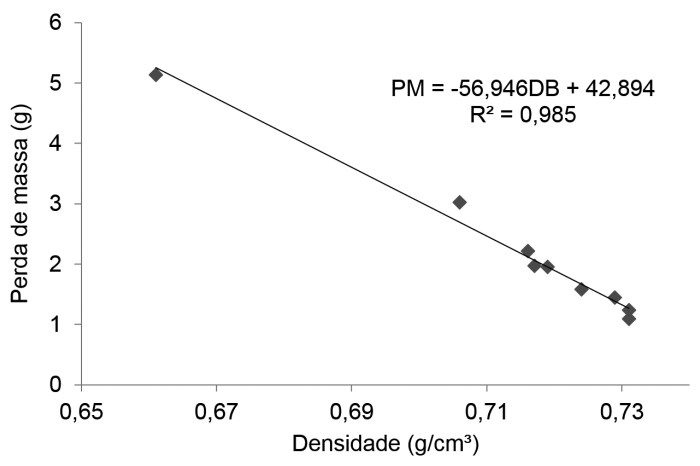

Figura 1. Relação entre a densidade básica e a perda de massa da madeira de Sclerolobium paniculatum. $\mathrm{PM}=$ perda de massa $(\mathrm{g}) ; \mathrm{DB}=$ densidade básica $\left(\mathrm{g} / \mathrm{cm}^{3}\right)$.

Figure 1. Relationship between basic density and mass loss of the Sclerolobium paniculatum wood. $\mathrm{PM}=$ weight loss $(\mathrm{g}) ; \mathrm{DB}=$ basic density $\left(\mathrm{g} \backslash \mathrm{cm}^{3}\right)$

De modo geral, a baixa perda de massa ocorrida é indício de que a madeira ensaiada é naturalmente resistente aos cupins do gênero Nasutitermes testados. Outro fator que possivelmente contribuiu para a alta resistência da espécie aos ataques dos térmitas foi a densidade da madeira.

Segundo Bowyer et al. (2003), madeiras que possuem densidade mais alta tendem a apresentar teores de extrativos mais elevados e uma maior resistência a organismos xilófagos. A densidade da madeira também influencia na habilidade de fragmentar mecanicamente o lenho dos térmitas, dificultando o seu consumo, comportamento coerente com o observado no presente trabalho, no qual as amostras com maior valor de densidade apresentaram menor perda de massa (Figura 1).

É preciso enfatizar que, apesar da relação entre o teor de extrativos e a densidade da madeira, o potencial de resistência natural não pode ser associado apenas a esses dois parâmetros, mas também com a classe química das substâncias existentes no lenho (Paes et al., 2007; Stangerlin, 2012).

\section{CONCLUSÕES}

A espécie promoveu alta mortalidade entre os cupins do gênero Nasutitermes, estando a perda de massa, o desgaste e mortalidade relacionados com a densidade da madeira de Sclerolobium paniculatum.
O dano causado pelos cupins à madeira de Sclerolobium paniculatum foi apenas superficial, tendo a mesma sido classificada como resistente ao ataque desses insetos, podendo ser indicada para uso em locais com incidência desses térmitas.

\section{STATUS DA SUBMISSÃO}

Recebido: 12 abr., 2016

Aceito: 25 abr., 2016

\section{AUTOR(ES) PARA CORRESPONDÊNCIA}

\section{Patricia Hellenn Stallbaun}

Departamento de Engenharia Florestal, Universidade Federal do Tocantins - UFT, Gurupi, Rua Badejós, Lote 7, Chácaras 69/72, Zona Rural, CP 66, CEP 77402-970, Palmas, TO, Brasil

e-mail: patriciahstallbaun@gmail.com

\section{REFERÊNCIAS}

Abreu RLS, Sales-Campos C, Hanada RE, Vasconcellos FJ, Freitas JA. Avaliação de danos por insetos em toras estocadas em indústrias madeireiras de Manaus, Amazonas, Brasil. Revista Árvore 2002; 26(6): 789-796.

American Society for Testing and Materials - ASTM. ASTM D-1413: standard test method for wood preservatives by laboratory soil-block cultures. West Conshohocken: ASTM; 2005a.

American Society for Testing and Materials - ASTM. ASTM D-2017: standard test method of accelerated laboratory test of natural decay resistance of wood. West Conshohocken: ASTM; 2005b.

American Society for Testing and Materials - ASTM. ASTM D-3345: standard test method for laboratory evaluation of wood and other cellulosic materials for resistance to termites. West Conshohocken: ASTM; 2005c.

Bandeira AG, Miranda CS, Vasconcellos A. Danos causados por cupins em João Pessoa, Paraíba - Brasil. In: Fontes LR, Berti E Fo, editores. Cupins: o desafio do conhecimento. Piracicaba: FEALQ; 1998. p. 75-85.

Bowyer JL, Shmulsky R, Haygreen JG. Forest products and wood science: an introduction. 4. ed. Iowa: Iowa State Press, 2003. 554p.

Carpanezzi AA, Marques LCT, Kanashiro M. Aspectos ecológicos e silviculturais de taxi-branco-da-terra-firme (Sclerolobium paniculatum). Curitiba: EMBRAPAURPFCS, $1983.10 \mathrm{p}$. 
Carvalho PER. Espécies arbóreas brasileiras [online]. Brasília: Embrapa Informação Tecnológica; 2010 [citado em 2015 dez 2]. Disponível em: http://livimagens.sct. embrapa.br/amostras/00083860.pdf

Constantino R. Chave ilustrada para identificação dos gêneros de cupins (Insecta: Isoptera) que ocorrem no Brasil. Papéis Avulsos de Zoologia 1999; 40(25): 387-448.

Costa AF, Vale AT, Gonzalez JC, Souza FDM. Durabilidade de madeiras tratadas e não tratadas em campo de apodrecimento. Floresta e Ambiente 2005; 12(1): 7-14.

Dias LE, Jucksch J, Alvarez VH, Barros NF, Brienza S Jr. Formação de mudas de táxi-branco (Sclerolobium paniculatum Vogel): resposta a nitrogênio, potássio e enxofre. Revista Árvore 1992; 16(2): 135-143.

Franke IL. Principais usos e serviços de árvores e arbustos promissores que ocorrem em pastagens no estado do Acre. Rio Branco: Embrapa Acre; 1999. 6 p.

Gomes JI, Silva EMA, Melo ATS. Durabilidade de 15 espécies de madeiras amazônicas em contato com o solo em ambiente sombreado. Belém: Embrapa Amazônia Oriental; 2005. 4 p.

Kambhampati S, Eggleton P. Taxonomy and phylogeny of termites. In: Abe T, Bignell DE, Higashi M, editores. Termites: evolution, sociality, symbioses, ecology. Netherlands: Kluwer Academic Publishers; 2000. p. 1-23. http://dx.doi. org/10.1007/978-94-017-3223-9_1.

Lima RMB. Crescimento do Sclerolobium paniculatum Vogel na Amazônia, em função de fatores de clima e solo [tese]. Curitiba: Universidade Federal do Paraná; 2004.

Lorenzi H. Árvores brasileiras: manual de identificação e cultivo de plantas arbóreas nativas do Brasil. 2. ed. Nova Odessa: Instituto Plantarum; 2002. 384 p. vol. 2.

Paes JB, Medeiros PN No, Lima CR, Freitas MF, Diniz CEF. Efeitos dos extrativos e cinzas na resistência natural de quatro madeiras a cupins xilófagos. Cerne 2013; 19(3): 399 405. http://dx.doi.org/10.1590/S0104-77602013000300006.

Paes JB, Melo RR, Lima CR. Resistência natural de sete madeiras a fungos e cupins xilófagos em condições de laboratório. Cerne. Lavras 2007; 13(2): 160-169.

Paes JB. Efeitos da purificação e do enriquecimento do creosoto vegetal em suas propriedades preservativas [tese]. Viçosa: Universidade Federal de Viçosa; 1997.

Panshin AJ, De Zeeuw C. Textbook of wood technology. 4. ed. New York: McGraw-Hill; 1980. 722 p.

Reis YT, Cancello EM. Riqueza de cupins (Insecta, Isoptera) em áreas de Mata Atlântica primária e secundária do sudeste da Bahia. Iheringia: Série Zoologia 2007; 97(3): 229-234. http://dx.doi.org/10.1590/S0073-47212007000300001.

Stangerlin DM, Costa AF, Garlet A, Pastore TCM. Resistência natural da madeira de três espécies amazônicas submetidas ao ataque de fungos apodrecedores. Ciência da Madeira 2013; 4(1): 15-32. http://dx.doi.org/10.12953/2177-6830. v04n01a02.

Stangerlin DM. Monitoramento de propriedades de madeiras da Amazônia submetidas ao ataque de fungos apodrecedores [tese]. Brasília: Universidade de Brasília; 2012.

Steel RGD, Torrie JH. Principles and procedures of statistic: a biometrical approach. 2. ed. New York: McGraw Hill; $1980.633 \mathrm{p}$.

Supriana N. Notes the resistance of tropical wood against termites. Stockholm: The International Research Group on Wood Preservation; 1985. 9 p. Doc. IRG/WP/1249.

Willeitner H. Laboratory tests on the natural durability of timber-methods and problems. Stockholm: The International Research Group on Wood Preservation; 1984.11 p. Doc. IRG/WP/2217. 